\title{
CO VICE-CHAIRS LETTER
}

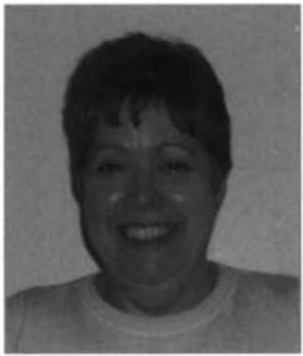

Chris Chiswell

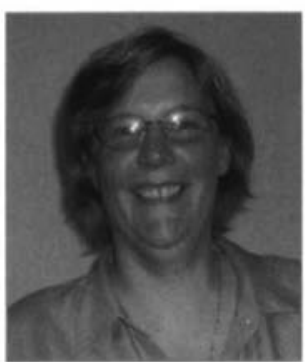

Inge D. Bateman
Due to personal circumstances our Chairperson Maddy Woods has unfortunately had to step down from the role. Chris Chiswell and I have stepped into the breach in our capacity of vice chair.

It is with great enthusiasm that Chris Chiswell and I have taken on the post of co vice-chairs since the reshuffle after the annual general meeting. You may wonder why it was decided that two people would fill this position. The workload within the committee is high and it is difficult to juggle the role of vice chair with professional and personal lives

As you know Chris is the Membership secretary. This in itself is a substantial job. Added to this she is active within the committee. I organise study days and also support the general work required within the committee all of which is done on a voluntary basis and in our free time; because of this we decided that it would be more realistic to have two vice-chairs. So as the saying goes "A burden shared is a burden halved!"

However at the last BARNA committee meeting Pat Smedley was elected as chair. Pat has recently returned from America and has been working really hard on BARNA's behalf. You will here more about Pat in the next issue. We wish Pat every success in her new role and will be supporting her.
The committee has decided that it is time for further development and change in BARNA. We have drafted some professional help with the planning and organisation of conference and study days with the purpose of freeing up committee members time to concentrate on issues such as setting national standards, networking with other countries, education and so on.

Obviously change takes time but you will hopefully see the benefits soon and share and support our vision, which is to promote excellence in Peri-anaesthetic care internationally. We encourage you to be actively involved and present your views to the committee to facilitate this process.

I hope you enjoyed the last Journal and made a note in your diary for the annual conference - June $25^{\text {th }}$ and $26^{\text {th }} 2002$, as well as applying for the study day in London on the $18^{\text {th }}$ March 2002. This promises to be an absolutely brilliant study day for those of you who have been working in anaesthetics and/or PACU for some time and find it is difficult to find study days that cater for your needs.

We are looking forward to seeing you at the study day.

$$
\text { Inyis Bres. Ohis Chiavell }
$$

Inge D. Bateman and Chris Chiswell Co Vice-chairs

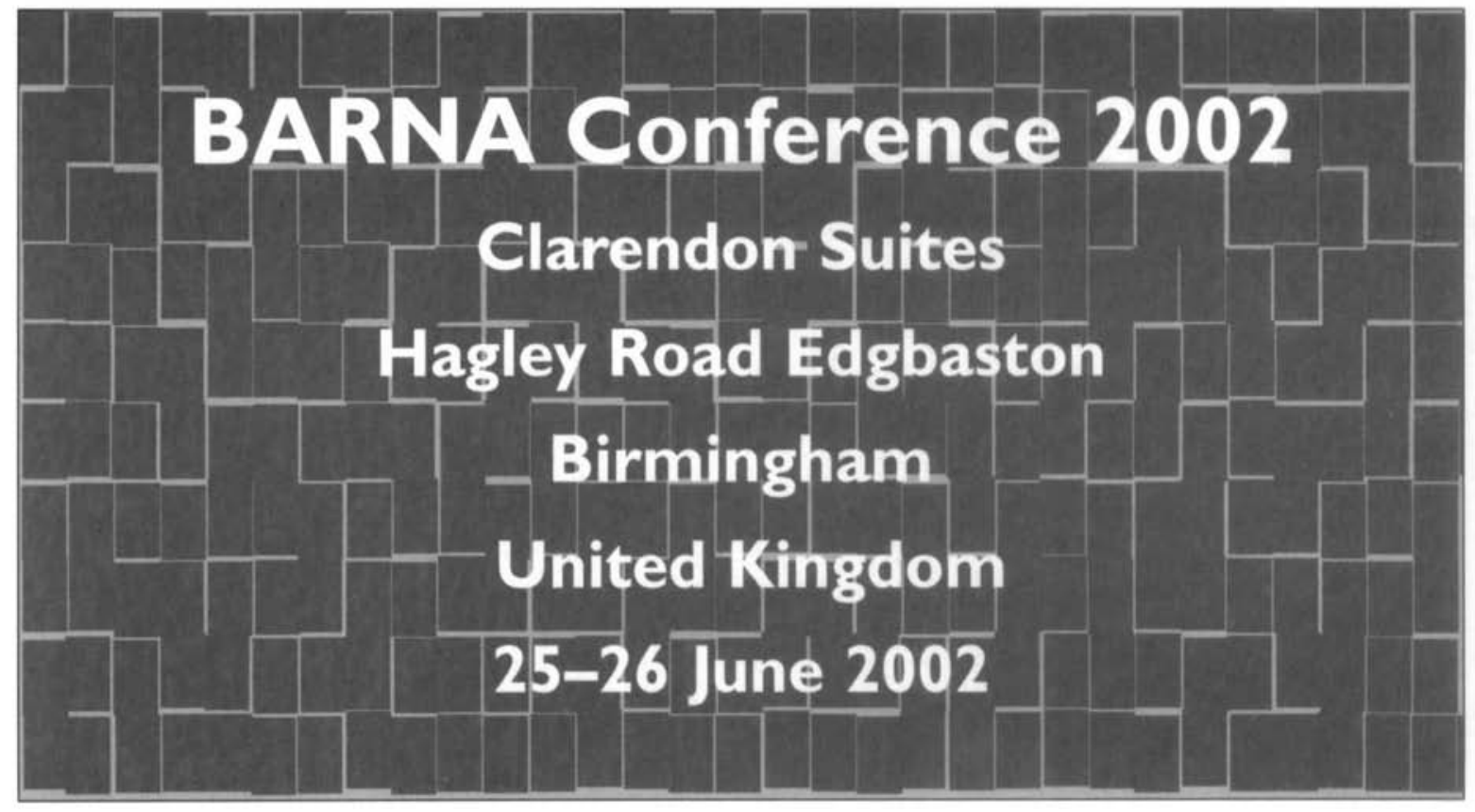

